\title{
Solubility Enhancement of Azithromycin by Solid Dispersion Method by using Polymer PVP K 90
}

\author{
Sanchay S Zinjad *, Devyani A Udmale, Akshada D Suryawanshi, S. L. Jadhav, D.D. Gaikwad \\ Vishal Institute of Pharmaceutical Education and Research Ale, Tal-Junnar, Dist-Pune (412411) Maharashtra, India
}

\begin{abstract}
Solubility is an important physicochemical factor affecting absorption of drug and its therapeutic effectiveness. In the solubility behavior of drugs remains one of the most exigent aspects in formulation development. Consequences of poor aqueous solubility would lead to failure in formulation development. Solubility enhancement leads to better absorption thus bioavailability improvement and Solid dispersions are investigated in many studies because they are highly versatile in their application. The poor solubility of drug substances in water and their low dissolution rate inaqueous G.I.T- fluid often leads to insufficient bioavailability. In the present investigation, an attempt were made to improve the solubility and dissolution rate of a poorly soluble drug, Azithromycin by solid dispersion method using PVP K 90 as carrier in 1:1,1:2,1:3,1:4 and 1:5 ratios. Solid dispersion of Azithromycin was prepared by solvent evaporation method. In vitro release profiles of solid dispersions in phosphate buffer pH 6.8 were comparatively evaluated and also studied against pure Azithromycin. Faster dissolution was exhibited by PVP K 90 Solid dispersion containing 1:4 ratio. The prepared Solid dispersions were subjected for Assay, saturation solubility studies in distilled water and phosphate buffer $\mathrm{pH} 6.8$.
\end{abstract}

Keywords: Azithromycin, PVP K 90, Solid dispersions, Methanol.

Article Info: Received 20 March 2019; Review Completed 22 April 2019; Accepted 30 April 2019; Available online 15 May 2019

\section{Cite this article as:}

Zinjad SS, Udmale DA, Suryawanshi AD, Jadhav SL, Gaikwad DD, Solubility Enhancement of Azithromycin by Solid Dispersion Method by using Polymer PVP K 90, Journal of Drug Delivery and Therapeutics. 2019; 9(3):121-124 http://dx.doi.org/10.22270/jddt.v9i3.2617

*Address for Correspondence:

Mr. Sanchay S. Zinjad, Department of M.Q.A., Vishal Institute of Pharmaceutical Education and Research,Ale, Tal-Junnar, Dist-Pune (412411) Maharashtra, India.

\section{INTRODUCTION}

Various techniques are used to enhance oral bioavailability of poorly water soluble drugs ${ }^{1}$. These strategies may include the use of surfactants, cyclodextrins, Micronization ${ }^{2}$, liquisolid techniques, Liposomes ${ }^{3}$, Ethosomes $^{4}$, Dendrimers ${ }^{5}$, solid dispersions ${ }^{6}$ and permeation enhancersand ${ }^{7}$.

\section{Solid dispersions 6 :}

Solid dispersions are investigated in many studies because they are highly versatile in their application. They can form the basis of products applied for various routes of administration and for various dosage forms, including the most popular oral dosage form.

\section{Advantages of Solid Dispersions ${ }^{8}$ :}

- Solubility enhancement leads to better absorption thus bioavailability improvement.

- Better patient compliance in the form of solid dosage form.
- Need not to conduct clinical trials as in case of chemical approaches i.e. Prodrug, salt formation.

- Broad application.

- Ease of formulation and manufacture.

\section{Disadvantages of Solid Dispersions:}

- During processing (mechanical stress) or storage (temperature and humidity stress) the amorphous state may undergo crystallization.

- Moisture may increase drug mobility and promote drug crystallization.

- Phase separation, crystal growth or conversion from the amorphous to the crystalline state or from a metastable crystalline form to a more stable structure during storage.

- Poor scale-up for the purposes of manufacturing.

Mechanisms of increased solubility due to solid dispersion ${ }^{6,8}$ :

- Size reduction of drug.

- Solubilization effect of the carrier. 
- Improved wettability and dispersability of drug.

- Dissolution of the drug in carrier.

- Conversion of the drug to amorphous state.

- Combination of any the above.

\section{The advantage of solid dispersion compared with conventional tablet/capsule formulations:}

From conventional capsules and tablets, the dissolution rate is limited by the size of the primary particles formed after the disintegration of dosage forms. In this case, an average particle size of $5 \mu \mathrm{m}$ is usually the lower limit, although higher particle sizes are preferred for ease of handling, formulation, and manufacturing. On the other hand, if a solid dispersion or asolid solution is used, a portion of the drug dissolves immediately to saturate the gastrointestinal fluid, and the excess drug precipitates out as fine colloidal particles of submicron size.

\section{MATERIALS AND METHOD}

Materials - Azithromycin, PVP K 90, Methanol.

\section{Method-}

Preparation of Physical mixtures: Five physical mixtures (PMs) of different proportions of azithromycin with PVP K 90 were prepared in the ratios of 1:1, 1:2, 1:3,1:4,1:5 w/w. The required amounts of azithromycin and PVP K 90 were weighed and mixed thoroughly by light trituration for $3 \mathrm{~min}$ in a glass mortar. The mixture was sieved and the powder fraction corresponding to mesh size less than 60 was collected for further investigation.

\section{Preparation of Solid dispersions6, 8, 9:}

\section{Solvent evaporation method:}

Polymers used include: PVP K 90. Drug and carriers were dissolved in common solvent methanol $30 \mathrm{ml}$. Then solvent was evaporated under room temperature. The experiment was carried out in dark because drug is light sensitive. The resultant mixtures were powdered in mortar, sieved through 60 mesh sieve and stored in cap vial at room temperature until evaluation.

\section{Characterization of Solid dispersions ${ }^{6,8,10}$ :}

\section{Angle of Repose:}

Angle of repose has been defined as the maximum angle possible between the surface of pile of powder and horizontal plane. The angle of repose for the granules of each formulation was determined by the funnel method. The prepared granules were allowed to flow out of the funnel orifice fixed at a height of $2 \mathrm{~cm}$ from the surface on a plane paper kept on the horizontal platform. The gradual addition of the granules from the funnel mouth forms a pile of granules at the surface this is continued until the pile touches the stem tip of the funnel. A rough circle is drawn around the pile base and the radius of the granule cone was measured. Angle of repose was then calculated with the use of the following formula:

$\operatorname{Tan} \theta=\mathrm{h} / \mathrm{r}$

Where, $\theta=$ angle of repose.

$\mathrm{h}=$ height of the pile.

$r=$ average radius of the powder cone.

\section{Bulk Density:}

Bulk density of the sample was determined by pouring gently $10 \mathrm{~g}$ of sample through a glass funnel into a $50 \mathrm{ml}$ graduated cylinder. The volume occupied by the sample was recorded. The bulk density will be calculated as follows:

Bulk Density $(\mathrm{gm} / \mathrm{ml})=$

Weight of sample in grams

Volume occupied by the sample

\section{Tapped Density:}

10 grams of sample was be poured gently through a glass funnel into a $50 \mathrm{ml}$ graduated cylinder. The cylinder will be tapped from height of 2 inches until a constant volume will be obtained. Volume occupied by the sample after tapping will be recorded and tapped density will be calculated as follows:

Tapped Density $(\mathrm{gm} / \mathrm{ml})=\quad$ Weight of sample in grams

Volume occupied by the sample

\section{Determination of Saturation Solubility:}

The shake flask method was used to determine saturation solubility of prepared solid dispersions in distilled water and phosphate buffer pH 6.8. Excess quantities of solid dispersions were added in $10 \mathrm{ml}$ distilled water and phosphate buffer pH 6.8 which is then incubated in orbital shaker at $37^{\circ} \mathrm{C}$ and at $100 \mathrm{rpm}$ for $24 \mathrm{hrs}$. Solutions were filtered through Whatman filter paper. Absorbance of resulting solutions was measured on UV spectrophotometer at $284.80 \mathrm{~nm}$ and $271.5 \mathrm{~nm}$ in distilled water and phosphate buffer $\mathrm{pH}$ 6.8. Saturation solubility was then calculated by putting measured absorbance value in calibration curve equation for distilled water and phosphate buffer $\mathrm{pH} 6.8$.

\section{Assay Preparation of Standard Solution:}

Azithromycin $10 \mathrm{mg}$ was weighed accurately and transferred to $10 \mathrm{ml}$ volumetric flask. It was dissolved in methanol and volume was made to $10 \mathrm{ml}$ with phosphate buffer $\mathrm{pH}$ 6.8. From this stock solution $(1000 \mu \mathrm{g} / \mathrm{ml}) .1 \mathrm{ml}$ solution was removed and diluted to $10 \mathrm{ml}$ with to get the solution of $10-0 \mu \mathrm{g} / \mathrm{ml}$. $1 \mathrm{ml}$ from this solution was taken and further diluted to $10 \mathrm{ml}$ with phosphate buffer $\mathrm{pH}$ 6.8. to obtain the solution of final concentration $10 \mu \mathrm{g} / \mathrm{ml}$. Absorbance of resulting solutions were measured on UV spectrophotometer at $271.5 \mathrm{~nm}$.

\section{Preparation of Sample Solution:}

Solid dispersion equivalent to $10 \mathrm{mg}$ azithromycin was weighed accurately and transferred to $10 \mathrm{ml}$ volumetric flask.. It was dissolved in methanol and volume was made to $10 \mathrm{ml}$ with phosphate buffer $\mathrm{pH}$ 6.8. From this stock solution ( $1000 \mu \mathrm{g} / \mathrm{ml}$ ). $1 \mathrm{ml}$ solution was removed and diluted to 10 $\mathrm{ml}$ with to get the solution of $100 \mu \mathrm{g} / \mathrm{ml} .1 \mathrm{ml}$ from this solution was taken and further diluted to $10 \mathrm{ml}$ with phosphate buffer $\mathrm{pH}$ 6.8. to obtain the solution of final concentration $10 \mu \mathrm{g} / \mathrm{ml}$. Absorbance of resulting solutions was measured on UV spectrophotometer at $271.5 \mathrm{~nm}$.

Assay was calculated by using equation:

Sample absorbance Assay $(\% \mathrm{w} / \mathrm{w})=$

$$
\text { Sample Absorbance } \times 100
$$

Standard absorbance

In vitro Dissolution studies of solid dispersion: In vitro dissolution studies were performed for solid dispersion using US Pharmacopoeia Dissolution Apparatus II (paddle 
type). An accurately weighed sample of solid dispersions (equivalent to $30 \mathrm{mg}$ azithromycin) was placed into $900 \mathrm{ml}$ of phosphate buffer ( $\mathrm{pH}$ 6.8), maintained at a temperature of $37^{\circ} \mathrm{C} \pm 0.5^{\circ} \mathrm{C}$ and stirred at a speed of $75 \mathrm{rpm}$. At $15 \mathrm{~min}$ time intervals, a $10 \mathrm{ml}$ aliquot of the sample was withdrawn and the volume was replaced with an equivalent amount of plain dissolution medium kept at $37^{\circ} \mathrm{C}$. The collected samples were filtered and analyzed at $\lambda$-max $271.5 \mathrm{~nm}$ using a UV visible spectrophotometer against phosphate buffer (pH 6.8) taken as blank.

\section{RESULT AND DISCUSSION}

Evaluation of powder blend-

Table 1: Data for evaluation of powder blend.

\begin{tabular}{|c|l|c|c|}
\hline Sr. No & Evaluations Test & \multicolumn{2}{|c|}{ RESULTS } \\
\hline & & SD & PM \\
\hline 1 & Bulk Density & 0.550 & 0.480 \\
\hline 2 & Tapped Density & 0.812 & 0.67 \\
\hline 3 & Angle Of Repose & 46.1 & 40.22 \\
\hline
\end{tabular}

Table 2: Solubility of physical mixtures in water.

\begin{tabular}{|c|c|c|c|c|c|}
\hline Sr.No & Polymer & Ratio & Saturation Solubility & \% Increase in Solubility & In Times \\
\hline 1 & \multirow{5}{*}{ PVP K 90} & $1: 1$ & 0.0413 & 124.45 & 2.24 \\
\hline 2 & & $1: 2$ & 0.0233 & 26.63 & 1.26 \\
\hline 3 & & $1: 3$ & 0.0336 & 82.60 & 1.82 \\
\hline 4 & & $1: 4$ & 0.0473 & 56.03 & 1.52 \\
\hline 5 & & $1: 5$ & 0.0281 & 157.06 & 2.57 \\
\hline
\end{tabular}

Table 3: Solubility of solid dispersion in water.

\begin{tabular}{|c|c|c|c|c|c|}
\hline Sr.No & Polymer & Ratio & Saturation Solubility & \% Increase in Solubility & In Times \\
\hline 1 & \multirow{5}{*}{ PVP K 90} & $1: 1$ & 0.0864 & 369.02 & 4.69 \\
\hline 2 & & $1: 2$ & 0.043 & 134.23 & 2.34 \\
\hline 3 & & $1: 3$ & 0.0895 & 386.81 & 4.86 \\
\hline 4 & & $1: 4$ & 0.0910 & 248.91 & 3.48 \\
\hline 5 & & $1: 5$ & 0.0642 & 394.56 & 9.94 \\
\hline
\end{tabular}

Table 4: Solubility ofphysical mixture in phosphate buffer.

\begin{tabular}{|c|c|c|c|c|c|}
\hline Sr.No & Polymer & Ratio & Saturation Solubility & \% Increase in Solubility & In Times \\
\hline 1 & \multirow{5}{*}{ PVP K 90} & $1: 1$ & 0.0464 & 25.40 & 1.25 \\
\hline 2 & & $1: 2$ & 0.0726 & 96.21 & 1.96 \\
\hline 3 & & $1: 3$ & 0.0538 & 45.40 & 1.45 \\
\hline 4 & & $1: 4$ & 0.0737 & 17.02 & 1.77 \\
\hline 5 & & $1: 5$ & 0.0433 & 99.18 & 1.99 \\
\hline
\end{tabular}

Table 5: solubility of solid dispersion in phosphate buffer.

\begin{tabular}{|c|c|c|c|c|c|}
\hline Sr.No & Polymer & Ratio & Saturation Solubility & \% Increase in Solubility & In Times \\
\hline 1 & \multirow{5}{*}{ PVP K 90} & $1: 1$ & 0.0514 & 38.92 & 1.38 \\
\hline 2 & & $1: 2$ & 0.0776 & 109.7 & 2.09 \\
\hline 3 & & $1: 3$ & 0.0588 & 58.91 & 1.58 \\
\hline 4 & & $1: 4$ & 0.0787 & 30.54 & 1.30 \\
\hline 5 & & $1: 5$ & 0.0483 & 112.7 & 2.12 \\
\hline
\end{tabular}

SDs prepared by solvent evaporation method for 1:5 ratio of PVP K 90showed maximum increase in Saturation solubility as compared to other ratios. However PVP K 90shows highest increase in solubility in phosphate buffer ( $\mathrm{pH}$ 6.8).

\section{Assay:}

The drug content of prepared solid dispersions was found to be in the range of 99 to $102 \% \mathrm{w} / \mathrm{w}$. The drug content values are shown in Table. Satisfactory reproducibility of results were observed when assay was repeated.

Table 6: Assay of solid dispersion and physical mixture.

\begin{tabular}{|c|c|c|c|c|}
\hline Sr.No & Polymer & Ratio & \multicolumn{2}{|c|}{ \% Assay } \\
\hline & & & PM & SD \\
\hline 1 & \multirow{4}{*}{ PVP K 90} & $1: 1$ & $100.18 \pm 0.04$ & $101.66 \pm 0.25$ \\
\hline 2 & & $1: 2$ & $100.01 \pm 0.15$ & $102.02 \pm 0.11$ \\
\hline 3 & & $1: 3$ & $99.95 \pm 0.22$ & $100.02 \pm 0.18$ \\
\hline 4 & & $1: 5$ & $100.02 \pm 0.34$ & $102.01 \pm 0.09$ \\
\hline
\end{tabular}




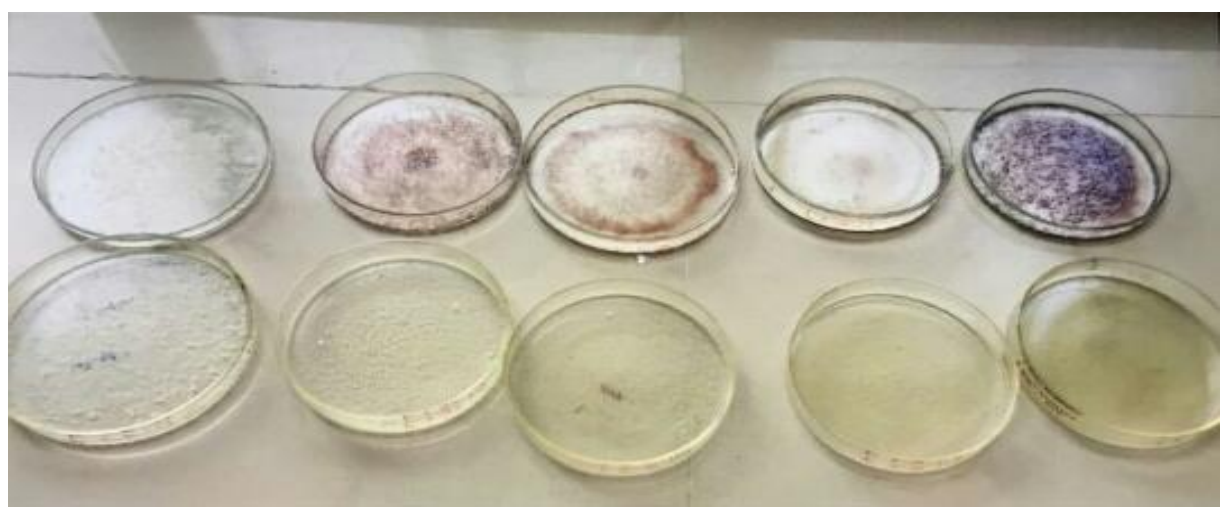

Figure 1: Prepared Solid dispersion

\section{Dissolution studies:}

Dissolution studies were carried out to determine the drug release profile from formulations and its comparison with that of pure drug. In vitro Dissolution studies in phosphate buffer pH $6.8 \%$ Drug release for PD, PM and prepared SDs is shown in Table No. 7.

Table 7: Cumulative Percent drug release of physical mixture in phosphate buffer pH 6.8.

\begin{tabular}{|l|l|c|c|}
\hline \multirow{2}{*}{ Time (Min) } & \multirow{2}{*}{ Pure Drug } & \multicolumn{2}{|c|}{$\begin{array}{c}\text { PVP K 90 } \\
\text { (1:4) }\end{array}$} \\
\cline { 3 - 4 } & & PM & SD \\
\hline 15 & 4.02 & 59.98 & 65.25 \\
\hline 30 & 14.33 & 72.01 & 76.81 \\
\hline 45 & 16.99 & 91.86 & 98.95 \\
\hline 60 & 22.25 & 98.05 & 106.18 \\
\hline
\end{tabular}

From dissolution studies, it was observed that, PD shown 22 $23 \%$ drug dissolved within $60 \mathrm{~min}$. which shows strong need to improve the dissolution. Solid dispersions prepared by solvent evaporation method for all the four polymers showed marked increase in the dissolution profile of drug release as compared to PD and PM. However complexation with PVP K 90 showed complete drug dissolution.

\section{CONCLUSION}

Azithromycin is a BCS class II drug having low solubility and high permeability. To improve upon the dissolution properties, solid dispersions of azithromycin were prepared in different ratios with carrier PVP K 90by solvent evaporation method. The prepared solid dispersions were evaluated by saturation solubility study, dissolution studies and drug content. From the findings of the study conducted, following conclusions can be drawn: Solid dispersions prepared with all the carriers improved the solubility as well as dissolution rate of azithromycin. Solid dispersion of PVP K 90was found to be more efficient in improving the drug solubility and dissolution rate.In-vitro drug release studies indicated complete drug release in 60 min.in as compared to pure drug having only $22-23 \%$ drug release in $60 \mathrm{~min}$. From all the observation it was concluded that solid dispersion with PVP K 90 [1:5] by solvent evaporation method showed marked improvement in solubility and dissolution. Capsule formulation of solid dispersion also proved better dissolution over pure drug.

\section{ACKNOWLEDGRMENT}

Authors are thankful to Vishal Institute of pharmaceutical education and research, Ale, Pune, for constant motivation and encouragement and also providing raw material to carry out this research work successfully. We would like to thank our principal Dr. Jadhav S. L. for providing us suitable environment for this work.

\section{REFERENCES}

1. Pande SV, Biyani KR, Microencapsulation by solvent evaporation method of BCS Class 4 drugs for bioavailability enhancement, Journal of Drug Delivery and Therapeutics. 2016; 6(5):18-30.

2. Rastogi V, Shukla S, Singh R, Lal N, Yadav P, Microspheres: A Promising Drug Carrier. Journal of Drug Delivery and Therapeutics, 2016; 6(3):18-26.

3. Vishvakrama P, Sharma S, Liposomes: An Overview. Journal of Drug Delivery and Therapeutics, 2014; 47-55.

4. Jaiswal P, Kesharwani S, Kesharwani R, Patel D, Ethosome: A New Technology Used As Topical \& Transdermal Delivery System. Journal of Drug Delivery and Therapeutics, 2016; 6(3):7-17.

5. Prajapati S, Maurya S, Das M, Tilak V, Verma K, \& Dhakar R. Dendrimers in Drug Delivery, Diagnosis and Therapy: Basics and Potential Applications. Journal of Drug Delivery and Therapeutics, 2016; 6(1):67-92.

6. Dalvi PB, Gerange AB, Ingale PR, Solid dispersion: strategy to enhance solubility, Journal of Drug Delivery and Therapeutics. 2015; 5(2):20-28.

7. Shah DP, Patel B, Shah C, Nanosuspension technology: A innovative slant for drug delivery system and permeability enhancer for poorly water soluble drugs, Journal of Drug Delivery and Therapeutics, 2015; 5(1):10-23

8. Chiou W. L., Riegelman, S., Pharmaceutical applications of solid dispersion systems. J. Pharm. Sci., 1971; 60(9):1281-302.

9. Bayomi M.A., Abanumay K.A., and Al-Angary A.A., Effect of inclusion complexation with cyclodextrins on photostability of nifedipine in solid state. Int. J. Pharm., 2002; 243(1-2):107-17.

10. Pinnamaneni, N. G., Das, N. G., Das, S.K.,. Formulation approaches for orally administered poorly soluble drugs. Pharmazee. 2002; 57(5):291-300. 